\title{
Electroluminescence in Ruthenium(II) Dendrimers ${ }^{\dagger}$
}

\author{
Jason A. Barron, Stefan Bernhard, Paul L. Houston, and Héctor D. Abruña \\ Department of Chemistry and Chemical Biology, Baker Lab, Cornell University, Ithaca, New York 14853-1301
}

\author{
Jennifer L. Ruglovsky and George G. Malliaras* \\ Department of Materials Science and Engineering, Cornell University, Ithaca, New York 14853-1501
}

Received: October 5, 2002; In Final Form: April 11, 2003

\begin{abstract}
We have investigated the electroluminescent properties of polyamidoamine dendrimers containing pendant $\left[\mathrm{Ru}(\text { bpy })_{3}\right]^{+2}$ chromophores. Devices were made using indium tin oxide (ITO) and gold electrodes, and they were compared to devices made from $\left[\mathrm{Ru}(\mathrm{bpy})_{3}\right]^{+2}$ films. The turn-on time, steady-state current, and electroluminescence efficiency were analyzed in order to provide information about the ionic and electronic carrier mobilities and the degree of self-quenching of luminescence in these materials.
\end{abstract}

\section{Introduction}

The use of polypyridyl complexes of transition metals as solid-state light-emitting devices has become a very exciting field in recent years. ${ }^{1-22}$ Previous studies of these materials in solution have shown very efficient light emission via electrogenerated chemiluminescence. ${ }^{23}$ Since a similar emission mechanism is proposed for the solid-state, high-efficiency devices based on thin films of these materials should be feasible. ${ }^{24}$ Indeed, high quantum efficiency and high radiant output have been achieved for organic light-emitting devices (OLEDs) based on ruthenium and osmium bipyridyl complexes. ${ }^{10,16-22}$ These complexes show great promise because they exhibit reversible and stable reduction and oxidation, as well as luminesce with reasonably high efficiency. These factors allow these materials to act both as hole and electron transporters and as emitters, thus reducing the number of device layers typically seen in conventional OLEDs. ${ }^{25}$ Moreover, the presence of an ionic space charge helps make the contacts ohmic, regardless of the metal work function, allowing for the fabrication of devices with airstable cathodes. ${ }^{21-22}$

The area of transition metal complex OLEDs has been discussed and separated into two branches of electroluminescent materials, one based on small molecules and the other based on polymers. ${ }^{18}$ The use of dendrimers as a support for the metal centers bridges the gap between these two branches. Dendrimers allow for control of the nanoscale dimensions of the molecular structure and influence over the physical properties of the films not possible in the small molecule regime. ${ }^{26}$ Further, the dendrimer architecture offers a unique environment for the chromophore not available in a two-dimensional polymer system. An example of this is the ability to create defined spaces at the nanoscale level. ${ }^{27}$ In this way, it may be possible to gain the benefits of both types of materials by retaining the chemical and color purity of the metal centers while increasing the robustness of the films.

\footnotetext{
† Part of the special issue "A. C. Albrecht Memorial Issue".

* Author to whom correspondence should be addressed at the Department of Materials Science and Engineering, Cornell University, 327 Bard Hall, Ithaca, NY 14853-1501. Tel: (607) 255-1956. Fax: (607) 255-2365. E-mail: george@ccmr.cornell.edu.
}

Electrically and optically active dendrimers for applications in organic light-emitting devices have already been reported in the literature. ${ }^{28-39}$ Dendrimers offer an interesting architecture for assembly of metal complexes. Many of the properties that make dendrimers potentially useful in other areas also make them useful in device design. They form in well-defined patterns that allow for control of weight, topology, cavity size, and surface functionality. The use of dendrimers in OLEDs allows for manipulation of spatial, electronic, surface-binding, and molecular interactions of the chromophores. For example, Freeman et al. ${ }^{35}$ have designed a dendrimer with arms that act as hole transporters, which transfer electrons to the strong acceptor fluorophore in the dendrimer core via a Förster process. Halim et al. ${ }^{34}$ and Lupton et al. ${ }^{36}$ used a phenylenevinylenebased dendrimer as the basis for an OLED. The dendrimer has a distyrylbenzene core for light emission and stilbene arms for charge transport. They were able to obtain good emission at $565 \mathrm{~nm}$ with external quantum efficiencies exceeding $0.1 \%$ for one generation of the dendrimer. By using dendrimers with a highly phosphorescent core and blending them with a host polymer, efficiencies of up to $8.1 \%$ were recently obtained. ${ }^{38}$

There are three general ways of incorporating metal complexes into dendrimer systems: (1) they can make up the core, (2) be part of the branching units, or (3) be bound to the ends of the dendrimer arms. These variations provide dramatically different chemical and spatial environments around the chromophore. By placing the chromophores at the end of the dendrimer arms, it is possible to effectively control the density and concentration of the metal centers, while at the same time allowing them to act independently. The result is a supramolecular architecture which can be described as a chromophoric sphere with an organic core. This architecture is also expected to provide rapid charge transport properties in the film.

A great deal of effort has been invested in designing and characterizing materials of this nature. ${ }^{41-44}$ We have synthesized and characterized a variety (generations $0-4$ with $4,8,16,32$, and 64 groups on the periphery, respectively) of polyamidoamine (PAMAM) dendrimers (Figure 1) containing pendant bipyridine ligands onto which $\mathrm{Ru}, \mathrm{Fe}, \mathrm{Co}, \mathrm{Re}$, as well as numerous other transition metal complexes may be attached through coordination. The interest in these materials was initially 

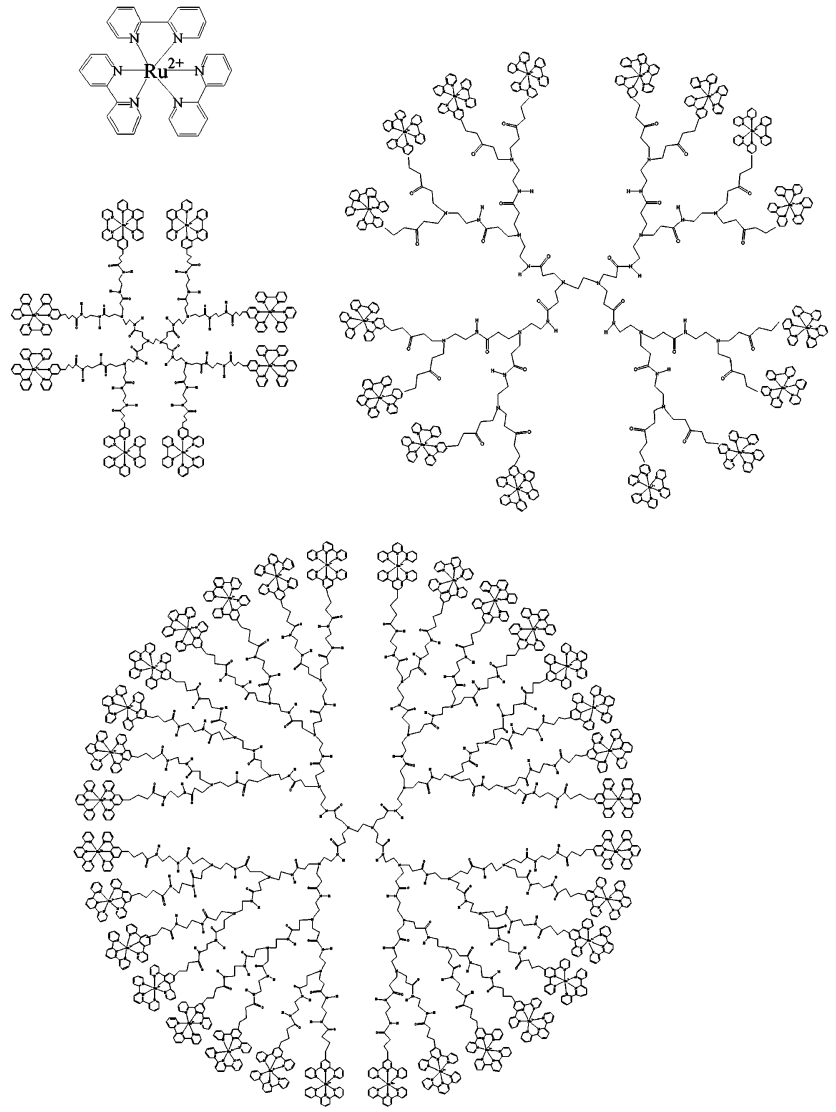

Figure 1. Chemical structure of the dendrimers.

stimulated not only by their redox chemistry but also by their photophysical behavior. In this regard, the study of dendrimers containing pendant $\left[\mathrm{Ru}(\mathrm{bpy})_{3}\right]^{+2}$ chromophores is of particular interest.

Previous results have suggested that while the metal complexes act independently of each other, the size and generation of the dendrimer affect their photophysics. ${ }^{44}$ This seems to be due, at least in part, to the folding nature of the dendrimers. As the dendrimers become larger they begin to displace the solvent around the chromophore and change its solvation. ${ }^{44}$ Further, the proximity of the chromophores changes as a function of the dendrimer generation. In the case of the poly(amidoamine) starburst dendrimers used in this paper, the proximity of the chromophores initially decreases from generation 0 to generation $2 .{ }^{44}$ In this regime, the additional bond length of each generation offsets the increase in the number of chromophores. In going from generation 2 to higher generations, de Gennes dense packing takes effect, the crowding factor rapidly increases, and we observe a significant decrease in the quantum efficiency of the molecules in solution. ${ }^{26,44,45}$ The use of these systems in OLEDs allows us to further elucidate what roles the concentration and density of the chromophore play in transport and luminescence. They also allow us to determine what effect the supramolecular architecture has on device performance and to gain further information on the role that the dendrimer structure plays on the photophysics of $\left[\mathrm{Ru}(\mathrm{bpy})_{3}\right]^{+2}$ in a solid-state environment.

\section{Experimental Section}

The synthesis, purification, and spectroscopic characterization of $\left[\mathrm{Ru}(\mathrm{bpy})_{3}\right]^{+2}$-PAMAM dendrimers (D- $n, n=1,2,3$ ) have been covered previously. ${ }^{41}$ The purity of the samples was confirmed by thin-layer chromatography, NMR, elemental analysis, and mass spectrometry. Devices were constructed using a pre-patterened ITO substrate (Thin Film Devices, Anaheim, CA) on 1-in. square glass slides. The substrates were first cleaned in a nonionic detergent bath, followed by a deionized water bath and UV/ozone treatment. Films were coated from solutions with concentrations of $12 \mathrm{mg}$ dendrimer/mL of acetonitrile. Spectroscopic grade acetonitrile was purchase from Burdick and Jackson and used as received. The solutions were filtered with a $0.2 \mu \mathrm{m}$ filter and degassed with ultrahigh purity nitrogen. The solutions were spin-cast onto ITO substrates in a dry nitrogen glovebox to give films that were approximately $80 \mathrm{~nm}$ thick. The films were dried for $12 \mathrm{~h}$ under vacuum at $100{ }^{\circ} \mathrm{C}$ and were reintroduced into the glovebox for further processing and characterization. A shadow mask was used to deposit $200 \AA$ thick Au cathodes. The mask defined six devices per substrate with a $3 \mathrm{~mm}^{2}$ active area each. Deposition was done in a stepwise, intermittent manner to minimize heating of the organic film. Electrical characteristics were measured via a Keithley 236 source-measure unit, while the radiance was measured with a calibrated UDT S370 optometer coupled to an integrating sphere. Current and radiance were typically measured at 30 -s intervals for $90 \mathrm{~min}$ or more. The electroluminescence spectra were measured with a calibrated S2000 Ocean Optics fiber spectrometer.

\section{Results and Discussion}

A thorough examination of the photophysical properties of this series of PAMAM-based dendrimers in solution at room temperature and in low temperature $(77 \mathrm{~K})$ glasses has been done previously. ${ }^{43,44}$ For the sake of completeness, the main points are summarized in Table 1. The electroluminescence (EL) spectra were found to be similar to the photoluminescence (PL) spectra from spin-coated films. The emission maxima are summarized in Table 1.

The device characteristics of OLEDs based on transition metal complexes have been the subject of past publications ${ }^{10,18-22}$ and appear to be consistent with the predictions of models developed by deMello et al. ${ }^{46}$ and Pichot et. al. ${ }^{47}$ Upon application of a bias, the negative counterions drift toward the anode (ITO), resulting in a current that decays with time. As these ions accumulate at the anode, they lower the barrier for hole injection. At the same time, the presence of uncompensated complexes in the neighborhood of the cathode enhances electron injection. As a result, the current becomes predominantly electronic in nature and begins to increase with time. At the same time, light is emitted from the sample as a result of the recombination of injected electrons and holes. As the electronic carrier density in the organic layer increases, the ions redistribute in accordance to the space charge field and the current reaches its equilibrium value. Since the ionic mobility is considerably smaller than that of the electronic carriers, the time scale for the device turn-on is dominated by ionic motion. This is clearly seen in Figure 2, which shows the evolution of current, radiance, and efficiency for devices made from the different dendrimers upon the application of $5 \mathrm{~V}$. The current in the devices made with generation 1 and 2 dendrimers shows all the regimes discussed above within the $90 \mathrm{~min}$ data acquisition window. The equilibration time for the $\left[\mathrm{Ru}(\mathrm{bpy})_{3}\right]^{+2}$ device is very fast compared to the time scale of the measurement, and the current appears to be constant. The generation 3 device took over $2 \mathrm{~h}$ to reach equilibrium (not shown here). The radiance, also shown in Figure 2, follows the evolution of the current (the data have been clipped below $5 \times 10^{-8} \mathrm{~W}$, which is the noise floor of 
TABLE 1: Comparison of Optical Properties and Device Characteristics for the Different Dendrimer Generations

\begin{tabular}{|c|c|c|c|c|c|c|}
\hline compound & $\begin{array}{l}\text { absorption } \\
\text { maximum }^{a} \\
\quad(\mathrm{~nm})\end{array}$ & $\begin{array}{c}\mathrm{PL} \\
\operatorname{maximum}^{a} \\
(\mathrm{~nm})\end{array}$ & $\begin{array}{c}\text { PL } \\
\text { efficiency }{ }^{a} \\
(\%)\end{array}$ & $\begin{array}{c}\text { EL } \\
\text { maximum }^{b} \\
(\mathrm{~nm})\end{array}$ & $\begin{array}{c}\text { EL } \\
\text { efficiency } \\
(\%)\end{array}$ & $\begin{array}{c}\mathrm{t}_{\mathrm{ON}}^{b} \\
(\mathrm{~min})\end{array}$ \\
\hline$\left[\mathrm{Ru}(\mathrm{bpy})_{3}\right]^{+2}$ & 450 & 606 & 6.6 & 609 & 0.22 & 1.5 \\
\hline D-1 & 454 & 616 & 2.4 & 613 & 0.12 & 5.5 \\
\hline D-2 & 454 & 617 & 2.1 & 608 & 0.06 & 7.0 \\
\hline D-3 & 454 & 617 & 2.1 & 606 & 0.05 & 135 \\
\hline
\end{tabular}

${ }^{a}$ Recorded at room temperature, in butyronitrile solution. ${ }^{b}$ Recorded at $5 \mathrm{~V}$ applied bias for all devices [the EL efficiency is voltage dependent ${ }^{22}$ ].
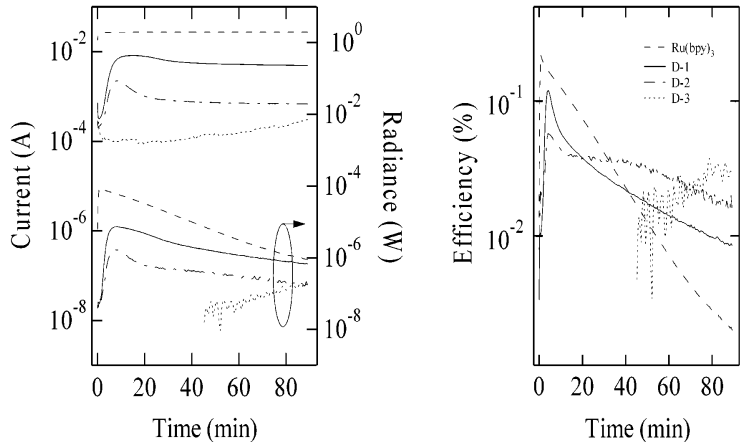

Figure 2. Temporal evolution of current, radiance, and efficiency for devices made from the different dendrimers upon the application of 5 V.

our detector). The time it takes to reach the maximum radiance, $t_{\mathrm{ON}}$, is shown in Table 1 to increase from $1.5 \mathrm{~min}$ for the $\left[\mathrm{Ru}(\mathrm{bpy})_{3}\right]^{+2}$, to $135 \mathrm{~min}$ for the generation 3 dendrimer. This is consistent with the fact that the ionic mobility is reduced as the molecular weight of the dendrimer increases. It should be noted that the voltage dependence of the device characteristics from the dendrimers was consistent with that observed in ruthenium and osmium complexes. ${ }^{10,21}$

Apart from slowing down the time to reach steady-state, increasing the generation of the dendrimer causes a lowering of the steady-state current. The steady-state current in these devices is due to electronic carriers that are injected from the electrodes. The injection of electronic carriers is efficient as a result of the formation of a charged layer at the interface $\left(\mathrm{PF}_{6}{ }^{-}\right.$ ions at the anode, uncompensated metal complexes at the cathode) which brings down the barriers for charge injection and makes the contacts essentially ohmic. ${ }^{22}$ The barrier lowering depends on the ion density, ${ }^{46}$ which does not vary much with generation. It is estimated to drop from $1.6 \times 10^{21} \mathrm{~cm}^{-3}$ for $\left[\mathrm{Ru}(\mathrm{bpy})_{3}\right]^{+2}$ to $1.1 \times 10^{21} \mathrm{~cm}^{-3}$ for the generation 3 dendrimer. As a result, the contacts should remain ohmic regardless of generation and the decrease in the current must reflect an intrinsic decrease in the mobility of electronic carriers as the dendrimers grow larger. Lupton et al. ${ }^{37,48}$ found that the hole mobility in phenylenevinylene dendrimers decreases as a function of generation, which was attributed to an increasing separation between the dendrimer cores. In the case of the $\mathrm{Ru}$ dendrimers, the lowering of the mobility of electronic carriers can be attributed to the dilution of the active metal centers in the electronically inactive PAMAM which comprises the core of the dendrimers.

The radiance in Figure 2a is shown to follow the current. Superimposed on that is a decay, which becomes apparent after the current has reached the steady-state (not visible on this time scale for the generation 3 dendrimer). This decay is also reflected in the EL (external quantum) efficiency, which is shown in Figure 2a. Although not shown on this plot, the efficiency for the generation 3 dendrimer follows the same trend as that of the other compounds. For a given material, the decay in radiance

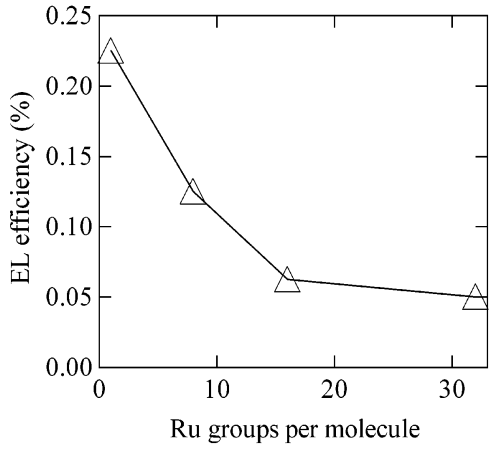

Figure 3. Electroluminescence efficiency as a function of dendrimer size.

was found to increase with the applied bias (i.e., the amount of current that flows through the sample), consistent with data in devices from $\mathrm{Ru}$ and Os complexes. ${ }^{10,21}$ At the same time, the magnitude of the EL efficiency is shown in Figure 3 to decrease with the generation of the dendrimer.

The EL efficiency of an OLED is given by ${ }^{25}$

$$
\eta=\mathrm{b} \cdot \varphi \cdot \mathrm{G}
$$

where $b$ is the recombination efficiency (fraction of electrons that recombine to form excitons), $\varphi$ is the fraction of excitons that decay radiatively, and $G$ is a factor that describes the efficiency with which light is coupled to the outside world. Emission in these materials arises from the triplet state, and any singlet exciton that is formed by charge injection is efficiently converted to a triplet. ${ }^{49}$ Therefore, $\varphi$ is the PL efficiency in the solid state. Since $b=1$ for ohmic contacts ${ }^{50}$ and $G$ is the same for all devices reported here, the decrease of $\eta$ with generation reflects a decrease of the PL efficiency in the solid state. The PL efficiency in solution (Table 1) shows the same trend, i.e., decreases monotonically going from $\left[\mathrm{Ru}(\mathrm{bpy})_{3}\right]^{+2}$ to the generation 3 dendrimer.

Typically, the PL efficiency of chromophores in the solid state is lower than that in solution due to self-quenching. It is instructive therefore to look at the ratio between the EL efficiency (thus, the PL efficiency in solid state) and the PL efficiency in solution, as it gives a measure of the degree of self-quenching. The data, shown in Figure 4, indicate that selfquenching increases with dendrimer generation, by as much as a factor of 2 in going from the generation 1 dendrimer to the generation 3 dendrimer. Overall, the dendrimers show a similar degree of self-quenching with the model compound $[\mathrm{Ru}-$ $\left.(\text { bpy })_{3}\right]^{+2}$. The degree of self-quenching depends chiefly on the distance between the chromophores, which depends on the precise configuration of the dendrimers which is not exactly known. ${ }^{42,43}$ We are currently investigating the spectroscopic properties of dendrimer films to gain a better understanding of the self-quenching of luminescence in these materials.

In conclusion, we have studied the electroluminescent properties of polyamidoamine dendrimers containing pendant $[\mathrm{Ru}-$ $\left.(\text { bpy })_{3}\right]^{+2}$ chromophores. Devices were made using ITO and Au 


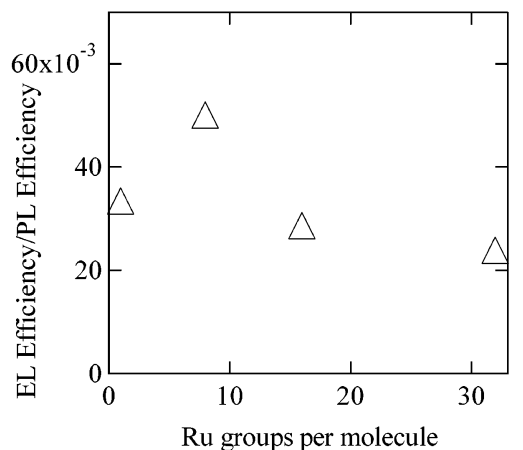

Figure 4. Ratio of electroluminescence to photoluminescence efficiency as a function of dendrimer size.

electrodes and were found to behave in a way similar to devices from $\left[\mathrm{Ru}(\mathrm{bpy})_{3}\right]^{+2}$ films. Both the ionic and the electronic mobility were found to decrease with increasing dendrimer generation, as manifested by the increase of the turn-on time and the decrease of the steady-state current, respectively. The efficiency also showed a monotonic decrease with generation, which was attributed to the decrease observed in the photoluminescence efficiency of the dendrimers. The generation 1 dendrimer exhibited the smallest degree of self-quenching of luminescence.

Acknowledgment. This work was supported by the Cornell Center for Materials Research (CCMR), a Materials Research Science and Engineering Center of the National Science Foundation (DMR-9632275) and by the National Science Foundation (Career Award DMR-0094047). S.B. acknowledges a Fellowship for Advanced Researchers from the Swiss National Science Foundation (Grant 8220-053387). We thank Katherine Smirl for help with the measurements.

\section{References and Notes}

(1) Lee, J.-K.; Yoo, D. S.; Handy, E. S.; Rubner, M. F. Appl. Phys. Lett. 1996, 69, 1686.

(2) Maness, K. M.; Terrill, R. H.; Meyer, T. J.; Murray, R. W.; Wightman, R. M. J. Am. Chem. Soc. 1996, 118, 10609.

(3) Lee, J.-K.; Yoo, D.; Rubner, M. F. Chem. Mater. 1997, 9, 1710. 1425 .

(4) Yoo, D.; Wu, A.; Lee, J.; Rubner, M. F. Synth. Met. 1997, 85,

(5) Maness, K. M.; Masui, H.; Wightman, R. M.; Murray, R. W. J. Am. Chem. Soc. 1997, 119, 3987.

(6) Handy, E. S.; Abbas, E. D.; Pal, A. J.; Rubner, M. F. Proc. SPIEInt. Soc. Opt. Eng. 1998, 3476, 62.

(7) Elliot, C. M.; Pichot, F.; Bloom, C. J.; Rider, L. S. J. Am. Chem. Soc. 1998, 120, 6781 . 663.

(8) Wu, A.; Lee, J.; Rubner, M. F. Thin Solid Films 1998, 327-329,

(9) Lyons, H.; Abbas, E. D.; Lee, J.-K.; Rubner, M. F. J. Am. Chem. Soc. 1998, 120, 12100.

(10) Handy, E. S.; Pal, A. J.; Rubner, M. F. J. Am. Chem. Soc. 1999, 121,3525 .

(11) Wu, A.; Yoo, D.; Lee, J.-K.; Rubner, M. F. J. Am. Chem. Soc. 1999, 121, 4883.

(12) Collinson, M. M.; Taussig, J.; Martin, S. A. Chem. Mater. 1999, $11,2594$. 899

(13) Collinson, M. M.; Martin, S. A. Chem. Commun. 1999, 899-900,

(14) Ng, W. Y.; Gong, X.; Chan, W. K. Chem. Mater. 1999, 11, 1165

(15) Chan, W. K.; Ng, P. K.; Gong, X.; Hou, S. J. Mater. Chem. 1999, $9,2103$.

(16) Rudmann, H.; Kaplan, L.; Sevian, H.; Rubner, M. F. Polym. Mater. Sci. Eng. 2000, 83, 235.

(17) Gao, F. G.; Bard, A. J. J. Am. Chem. Soc. 2000, 122, 7426.

(18) Rudmann, H.; Rubner, M. F. J. Appl. Phys. 2001, 90, 4338.

(19) Rudmann, H.; Shimada, S.; Rubner, M. F. J. Am. Chem. Soc. 2002 124,4918

(20) Buda, M.; Kalyuzhny, G.; Bard, A. J. J. Am. Chem. Soc. 2002, 124, 6090 .

(21) Bernhard, S.; Gao, X.; Abruña, H. D.; Malliaras, G. G. Adv. Mater. 2002, 14, 433.

(22) Bernhard, S.; Barron, J. A.; Houston, P. L.; Abruña, H. D.; Ruglovksy, J. L.; Gao, X.; Malliaras, G. G. J. Am. Chem. Soc. 2002, 124, $1272-1278$

(23) McCord, P.; Bard, A. J. J. Electoanal. Chem. 1991, 318, 91.

(24) Tokel, N. E.; Bard, A. J. J. Am. Chem. Soc. 1972, 94, 2862.

(25) Scott, J. C.; Malliaras, G. G. Conjugated Polymers; Hadziioannou, G., van Hutten, P. F., Eds.; Wiley-VCH: New York, 1999; Chapter 13

(26) Tomalia, D. A. High Perform. Polym. 2001, 13, S1-S10.

(27) Esfand, R.; Tomalia, D. A. Chem. Ind. 1997, 11, 416.

(28) Dandliker, P. J.; Diederich, F.; Gross, M.; Knobler, C. B.; Louati,

A.; Sanford, E. M. Angew. Chem., Int. Ed. Engl. 1994, 33, 1739.

(29) Shirota, Y.; Kuwabara, Y.; Inada, H.; Wakimoto, T.; Nakada, H.;

Yonemoto, Y.; Kawami, S.; Imai, K. Appl. Phys. Lett. 1994, 65, 807.

(30) Wang, P. W.; Liu, Y. J.; Devadoss, C.; Bharathi, P.; Moore, J. S. Adv. Mater. 1996, 8, 237.

(31) Bettenhausen, J.; Strohriegl, P. Adv. Mater. 1996, 8, 507.

(32) Miller, L. L.; Duan, R. G.; Tully, D. C.; Tomalia, D. A. J. Am. Chem. Soc. 1997, 119, 1005.

(33) Deb, S. K.; Maddux, T. M.; Yu, L. J. Am. Chem. Soc. 1997, 119 , 9079

(34) Halim, M.; Pillow, N. G.; Samuel, I. D. W.; Burn, P. L. Adv. Mater. 1999, 11,371

(35) Freeman, A. W.; Koene, S. C.; Malenfant, P. R. L.; Thompson, M. E.; Fréchet, J. M. J. J. Am. Chem. Soc. 2000, 122, 12385.

(36) Lupton, J. M.; Samuel, I. D. W.; Frampton, M. J.; Beavington, R.; Burn, P. L. Adv. Funct. Mater. 2001, 11, 287.

(37) Lupton, J. M.; Samuel, I. D. W.; Frampton, M. J.; Beavington, R.; Burn, P. L.; Bässler, H. Adv. Mater. 2001, 13, 258.

(38) Markham, J. P. J.; Lo, S.-C.; Magennis, S. W.; Burn, P. L.; Samuel, I. D. W.; Appl. Phys. Lett. 2002, 80, 2645.

(39) Fréchet, J. M. J.; Hecht, S. Angew. Chem., Int. Ed. 2002, 40, 74

(40) Jiang, D. L.; Aida, T. In Dendrimers and Other Dendritic Polymers Fréchet, J. M. J., Tomalia, D. A., Eds.; J. Wiley \& Sons: West Sussex, 2001; pp 425-439.

(41) Storrier, G. D.; Takada, K.; Abruña, H. D. Langmuir 1999, 15, 872.

(42) Takada, K.; Storrier, G. D.; Moran, M.; Abruña, H. D. Langmuir 1999, 15,7333

(43) Glazier, S.; Barron, J. A.; Houston, P. L.; Abruña, H. D. J. Phys. Chem. B 2002, 106, 9993-10003.

(44) Glazier, S.; Barron, J. A.; Morales, N.; Ruschak, A. M.; Houston, P. L.; Abruna, H. D. Macromolecules 2003, 36, 1272-1278.

(45) Tomalia, D. A.; Fréchet, J. M. J. In Dendrimers and Other Dendritic Polymers; Fréchet, J. M. J., Tomalia, D. A., Eds.; J. Wiley \& Sons: West Sussex, 2001; pp 3-44.

(46) deMello, J. C.; Tessler, N.; Graham, S. C.; Friend, R. H. Phys. Rev. B 1998, 57, 12951.

(47) Pichot, F.; Bloom, C. J.; Rider, L. S.; Elliott, C. M. J. Phys. Chem. $B$ 1998, 102, 3523 .

(48) Lupton, J. M.; Samuel, I. D. W.; Frampton, M. J.; Beavington, R. Burn, P. L.; Bässler, H. Synth. Met. 2001, 121, 1703.

(49) Kalyanasundaram, K. Photochemistry of Polypyridine and Porphyrin Complexes; Academic Press: London, 1992.

(50) Malliaras, G. G.; Scott, J. C. J. Appl. Phys. 1998, 83, 5399. 